\title{
The Booming Social Media and Increasing Perceptual Loneliness: The Scientific Co-Relational Study
}

\author{
Dr. Prashant G. Sonawanen ${ }^{1 *}$, Dr. Karuna S. Wankhade ${ }^{2}$
}

\section{ABSTRACT}

Day by day the world is coming closer and closer, and the communication is becoming super quick than ever, just at the finger tips of a person. And social media played an important role in it, where you can communicate with the group at a time whenever and wherever you wish so. This has done marvelous change in the communication of people and it proved great asset, but at the same time it is creating a sort of virtual and superficial bonds in the relations which are not able to give the feel of connectedness in a true sense. Many of the studies that are done shows that, the social mediums which are opening communication on the broad platform, but at the same time creating the loneliness feeling deep within and which is increasing day by day.

So the present study attempts to understand the co-relation between these two issues scientifically. Present study is done with the help of standardized perceptual Loneliness scale by Dr. Praveen Kumar Zha, and a Non-standardized scale for measuring the extent of the use of social media constructed by researcher. Samples are the individuals from adolescent to adult age group, of various professions, who are using the social media in significant and variable ratio. Result of the study concluded that there is positive correlation in both these variables. Implications and suggestions for the study are highlighted. Suggestions for further study are offered.

Keywords: Social Media, Perceptual Loneliness

One day while I was travelling in the train, I observed that many passengers from the train were busy with their cell phones and were not communicating with each other, after some time when they got bored with the things they were doing, they changed the tasks they were doing in cell phones, but didn't communicated with anyone else in that bogie. I thought this was the very

\footnotetext{
${ }^{1}$ M.D. (Hom) (Psychiatry), Clinical Psychologist, Assistant Prof. Psychology Dept. Bhonsala Military College, Nashik, Maharashtra, India

${ }^{2}$ M.D. (Hom) (Psychiatry), Associate Professor - Motiwala Homoeopathic Medical College, Nashik, Maharashtra, India

*Responding Author

(C) 2016, P Sonawanen, K Wankhade; licensee IJIP. This is an Open Access Research distributed under the terms of the Creative Commons Attribution License (http://creativecommons.org/licenses/by/2.0), which permits unrestricted use, distribution, and reproduction in any Medium, provided the original work is properly cited.
} 
different scene from earlier days of the travel, when everyone used to communicate with accompanying passengers in a realistic way, used to share thoughts with each other. But this scene was very different from that. This scene provoked many thoughts in my mind, being the mental health worker, it was the observation and study of mine that the perceptual loneliness is increasing day by day, perceptual loneliness is that when there is no feeling of connectedness or companionship even though the person is not physically lonely. So the questions started bouncing in my mind that, Is there any role of the mechanical and virtual relations made by the overtly growing social media for creating perceptual loneliness? So the attempt is made to study this co-relation.

\section{Loneliness:}

Loneliness is a complex and usually unpleasant emotional response to isolation or lack of companionship. Loneliness typically includes anxious feelings about a lack of connectedness or communality with other beings, both in the present and extending into the future.

\section{Feeling lonely vs. being socially isolated:}

Feeling lonely and being really socially lonely are two completely different things. Feeling loneliness is the perceived un-connectedness with others even though surrounded by people, even though the social connections are available around. And solitude is the real social isolation due to some and other reason. So loneliness is more a subjective perception or experience. Loneliness is therefore a subjective experience; if a person thinks they are lonely, then they are lonely. People can be lonely while in solitude, or in the middle of a crowd.

\section{Effects of loneliness:}

\section{Mental health:}

Loneliness is very important etiological factor for the depression and its variants and becomes the responsible for suicidal behavior also. Emile Durkheim has described loneliness, specifically the inability or unwillingness to live for others, i.e. for friendships or altruistic ideas, as the main reason for what he called egoistic suicide. (Marano, Hara Estroff, 2003).

Loneliness is one of the main risk factor for the substance abuse also specifically alcoholism. In females the loneliness feeling is major precipitating factor for various mental illnesses such as dysthymia, somatoform disorders, and various anxiety disorders. In children, feelings of loneliness, is creating the Hyperactive and antisocial behavior. It also affects the intellectual capability of an individual and the same time it affects the various vegetative functions which are good indicators of physical health that is sleep patterns, digestion, and other physiological disturbances. 


\section{The Booming Social Media And Increasing Perceptual Loneliness: The Scientific Co-Relational Study}

\section{Physical health:}

There are enough evidences that the feeling of loneliness in chronic way creates serious health conditions. One study has scientifically stated that there is increased risk of the cancer if one harbors feelings of loneliness for long. Chronic Loneliness feelings are also prominent precipitating factor in creating the chronic physical illnesses such as cardiovascular illness, Hypertension, High Cholesterol, improper increase in weight, and the GIT disturbances. Loneliness is Linked with the Immunity of human body, and the intensity and the progression of the chronic illnesses is seen to be affected by the loneliness in substantial way.

\section{Social media:}

A study reveals that India has recorded world's largest growth in terms of Social Media users in 2014.

Social media is platform at which the social relations and the communication gets created easily, and it is the medium which easily can form the communication in various ways among the members of that group. So with the help of the social media one can share his background, interests, hobbies, likes and dislikes, in short the communication gets started. Now a day there is marked revolution in the social communication and these social mediums had played a significant role for it. Most social network services are web-based and provide means for users to interact over the Internet, such as e-mail and instant messaging. Most popular social mediums are whatsapp, Facebook, Twitter, Google+, Youtube, Instagram, Pintrest, Vine and Tumblr.

\section{Psychological effects of social networking:}

There are sufficient evidences that people are spending an excessive time with their smart phones and with internet on their personal computers. It is up to the extent that researchers could reach to conclusion of establishment of the internet addiction disorder as actual clinical entity.

Social networking at the same time produces a bundle of negative emotions such as jealousy, envy, grid due to various complex mechanisms involved in the understanding others status at the social media platforms. It is also seen to be creating the sense of inferiority complex within oneself. So at times person represent himself in more appreciable and acceptable way than really he is which results altogether in more stress.

In a Newsweek article, Johannah Cornblatt explains "Social-networking sites like Facebook and MySpace may provide people with a false sense of connection that ultimately increases loneliness in people who feel alone”.

John T. Cacioppo, a neuroscientist at the University of Chicago, claims that social networking can foster feelings of sensitivity to disconnection, which can lead to loneliness. Fabio Sabatini and Francesco Sarracino found that if an individual tends to trust people and have a significant 
number of face-to-face interactions, the individual is likely to assess their own well-being as relatively high.

The researchers found that online social networking plays a positive role in subjective well-being when the networking is used to facilitate physical interactions, but networking activities that do not facilitate face-to-face interactions tend to erode trust, and this erosion can then negatively affect subjective well-being (independent of the online social interaction itself).

Sabatini and Sarracino conclude that "The overall effect of networking on individual welfare is significantly negative. However, some scholars have expressed that concerns about social networking are often exaggerated and poorly researched.

\section{Current Status about Social Media:}

"Social media usage continues to grow around the world, with global penetration rates now in excess of 30\%. Facebook continues to dominate the global landscape, accounting for almost 1.5 billion users. The world's favorite social platform shows little sign of losing its grip either, with 180 million new users joining the community over the past 12 months, up 13.7\% year-on-year. (Prashant Naidu, Sept 2015).

One study done by the agency "We are social" studied the social, digital and mobile usage in India in 2015. These are the study about the mediums os social media used mostly, by which age group and with what Medias. And it concluded that the mostly
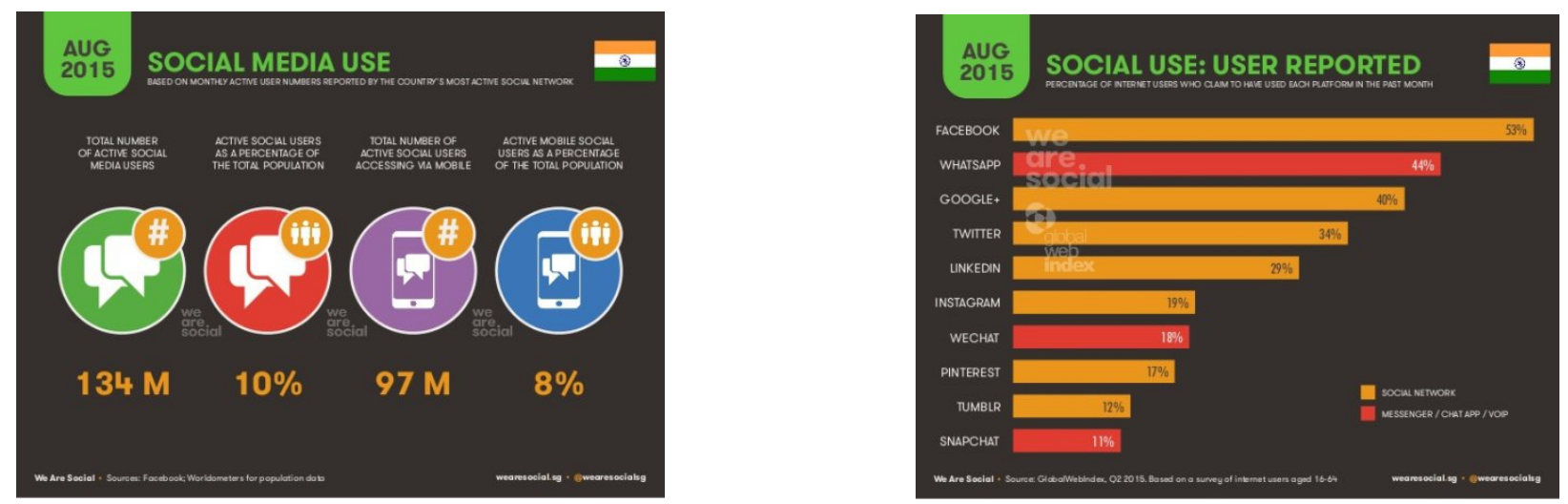

Fig.1\&2 : Extent of the social media use and the popular media of engaging in the social media. 
The Booming Social Media And Increasing Perceptual Loneliness: The Scientific Co-Relational Study
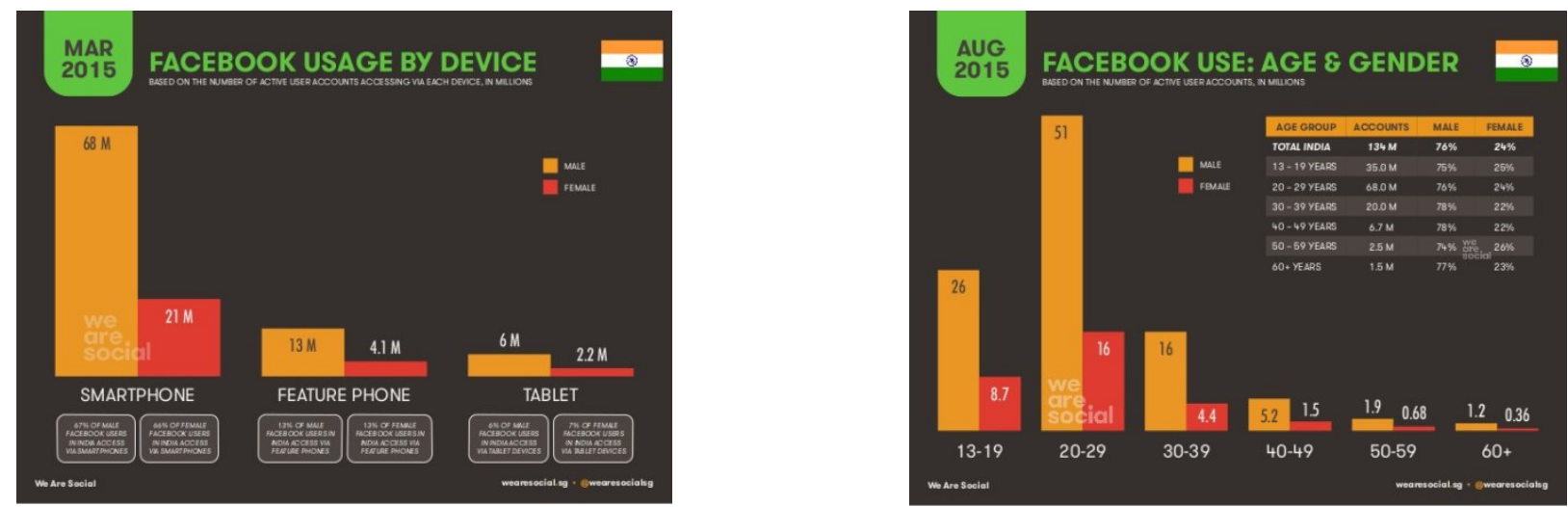

Fig. 3\& 4: Extent of the meium with with the social meduim are accessed and the most vulnerable age group.

\section{MATERIALS AND METHODS}

54 Samples are taken for study, from age group adolescent to adults, from various professions, 12 questionnaires are given in person, and 18 questionnaires are mailed to subjects and instructions are told on phone.

Subjects are included; those are having smart phones and uses social media such as whatsapp, facebook, telegram and other mediums on the internet.

Subjects who are having some psychological issues and living physically alone are excluded from the study.

\section{Instruments of the study:}

1. Perceptual loneliness scale by Dr. Praveen Kumar Zha:

Standardized scale has 36 items, this scale possess fairly high reliability. Two indices of reliability of L-scale were determined. Firstly, it was determined by Kuder - Richardson formula and the obtained value was to be 0.65 and validity is 0.001 levels on a sample of 100 undergraduate students.

\section{Scale to measure the Extent of Use of Social Media:}

This is the nonstandard scale made by researcher to measure the use of extent of the social media. This scale is based on the facts of using social media and various habits that denotes the extent of use.

\section{Observations and Discussions:}

The scores of both the scales are noted, it shown a range of the scores in all 54 subjects, then for the correlation of both the scores the Pearson's Correlation Coefficient is calculated, which is seen to be 0.40 , which concludes that there is significant positive correlation between the Perceptual loneliness and Extent of Use of Social Media.

(C) The International Journal of Indian Psychology, ISSN 2348-5396 (e) | ISSN: 2349-3429 (p) | 167 
The Booming Social Media And Increasing Perceptual Loneliness: The Scientific Co-Relational Study

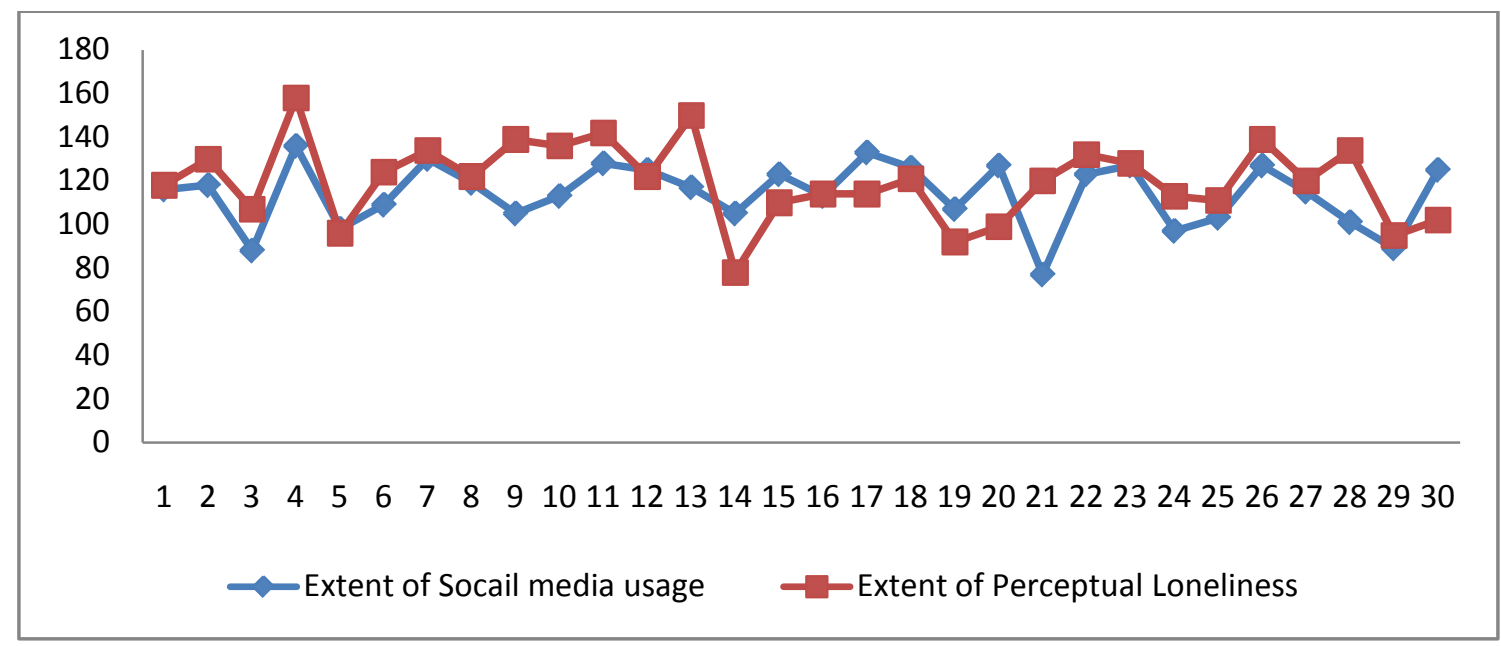

Fig 1: correlation of the Extent of the Social Media Usage and the Extent of Perceptual Loneliness

Scatter plot of the correlation between the Extent of the social Media usage and the Extent of the perceptual Loneliness found:

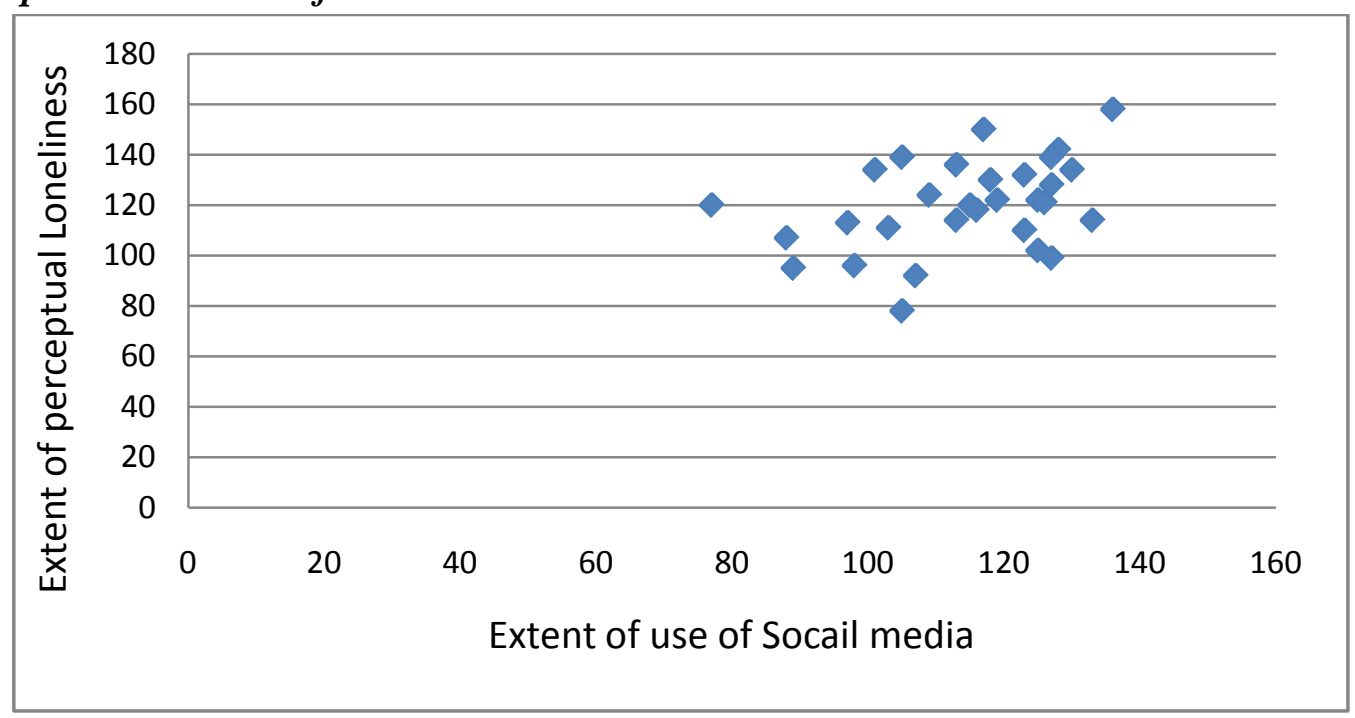

The cause and effect relationship can't be obtained in this study as Perceptual Loneliness has a multi-factorial origin. But with the help of above study the significant positive relationship is scientifically proved.

\section{IMPLICATIONS OF THE STUDY}

As social media and all the modern technology is surely beneficial to a great extent but the kind and amount of use of it decides whether it acts as a boon or curse to us, so the use of the social media should be done in a way that the perfect balance should be maintained.

(c) The International Journal of Indian Psychology, ISSN 2348-5396 (e)| ISSN: 2349-3429 (p) | 168 


\section{LIMITATIONS AND RECOMMENDATIONS}

The sample size used for the study is relatively small that is fifty four, and the stress levels and social background has the tremendous effect on the perceptual loneliness so these factors remained as extraneous variables in the study. Then the personality type also acts the significant factor in Perceptual loneliness so further studies should be done with keeping these variables in mind.

\section{Acknowledgments}

The author appreciates all those who participated in the study and helped to facilitate the research process.

\section{Conflict of Interests}

The author declared no conflict of interests.

\section{REFERENCES}

"Loneliness." Wikipedia: The Free Encyclopedia. Wikimedia Foundation, Inc., 7 Nov. 2012. Web. 25 Nov. 2012. < https://en.wikipedia.org/wiki/Loneliness

Alex Greig 2013 http://www.dailymail.co.uk/news/article-2419419/All-lonely-Facebook-friendsStudy-shows-social-media-makes-MORE-lonely-unhappy-LESSsociable.html\#ixzz3K4hP0V6j

Capuzzi, D., \& Gross, D.R. (2008). Counselling and Psychotherapy: theories and interventions 4th Edn. Pearson Education: India.

Dr. Praveen Kumar Jha (1999) perceived loneliness scale (L- Scale) psycho Prasad, Delhi, p 3-7. Kothari, C.R., 1985, Research Methodology-Methods and Techniques, New Delhi, Wiley Eastern Limited.

Robert s. Feldman (2002) “Understanding Psychology “Sixth Edition.

How to cite this article: P Sonawanen, K Wankhade (2016), The Booming Social Media And Increasing Perceptual Loneliness: The Scientific Co-Relational Study, International Journal of Indian Psychology, Volume 3, Issue 4, No. 65, ISSN 2348-5396 (e), ISSN: 2349-3429 (p), DIP: 18.01.148/20160304, ISBN: 978-1-365-34680-4

(c) The International Journal of Indian Psychology, ISSN 2348-5396 (e)| ISSN: 2349-3429 (p) | 169 